\title{
Spørreskjema gir bedre oppfølging av unge voksne med diabetes type 1
}

Det kan være psykososialt belastende å ha diabetes type 1 . Diabetesrelaterte bekymringer kan kartlegges gjennom spørreskjemaet PAID.

\section{Ingvild Hernar}

Diabetessykepleier og høgskolelektor

Haukeland universitetssjukehus og Institutt for helse- og omsorgsvitskap, Høgskulen på Vestlandet

\section{Anne Haugstvedt}

Professor

Institutt for helse- og omsorgsvitskap, Høgskulen på Vestlandet
Ungdom
Diabetes
Forebygging

\section{Hovedbudskap}

Blant personer med diabetes type 1 kan psykososiale belastninger ved å leve med sykdommen være en vesentlig barriere for å oppnå anbefalte behandlingsmål. I henhold til internasjonale retningslinjer anbefales det å bruke pasientrapporterte målinger (PROM) for å kartlegge diabetesrelaterte bekymringer. I prosjektet DiaPROM har vi utviklet og testet en empowermentbasert intervensjon der vi benyttet spørreskjemaet Problem Areas In Diabetes (PAID) i poliklinisk oppfølging av unge voksne med diabetes type 1. 
Diabetes type 1 er en krevende sykdom å leve med (1). Til tross for stadige medisinske og teknologiske innovasjoner er det mange som strever med å oppnå anbefalte behandlingsmål (2).

Både biomedisinske og psykososiale faktorer og et samspill mellom disse kan være viktige barrierer for god egenbehandling. Faktorene kan dermed være medvirkende årsaker til at kun 20-30 prosent av unge voksne oppnår anbefalte mål for kroppens glukoseregulering $(2,3)$. Det er derfor viktig å ha en systematisk tilnærming til både psykososiale og biomedisinske aspekter i diabetesoppfølgingen.

Diabetesrelatert bekymring (diabetes distress) (4) er et begrep som brukes om den emosjonelle belastningen ved å leve med og håndtere diabetes (5). Bekymringene er forventede reaksjoner som kan påvirke generelt velvære.

\section{«Om lag 20-40 prosent av voksne med diabetes type 1 opplever å ha forhøyet distress.»}

Om lag 20-40 prosent av voksne med diabetes type 1 opplever å ha forh øyet distress, som oftest knyttet til insulinbehandlingen, frykt for hypoglykemi samt bekymring for fremtiden og langsiktige komplikasjoner $(5,6)$.

Forskning tyder på at diabetesrelatert bekymring er mer utbredt blant yngre enn eldre voksne (7). Bekymringen regnes ikke som psykopatologi i seg selv (8), men er likevel vist å være en risikofaktor for å utvikle depresjon (9).

Derfor anbefaler eksperter på feltet og internasjonale retningslinjer regelmessig kartlegging og økt søkelys på psykososiale aspekter i oppfølgingen av personer med diabetes type $1(4,5)$.

\section{Diabetesoppfølging kan være krevende}

Helsepersonell har betydningsfulle roller overfor personer med diabetes type 1, spesielt når det gjelder medisinsk oppfølging, opplæring og helhetlig omsorg (10). Diabetesoppfølging kan også være krevende for helsepersonell på grunn av forventninger om at man skal yte personsentrert omsorg og samtidig dokumentere en mengde biomedisinske målinger og observasjoner.

Personsentrert oppfølging og omsorg er basert på empowerment-tenkningen, der helsepersonellets mål er å støtte og motivere pasienten til å håndtere sykdommen sin selv og ta informerte valg knyttet til egenbehandling (11). Empowermentbaserte diabetesintervensjoner har vist seg å forbedre både biomedisinske og psykososiale utfallsmål (12). 
Pasientrapporterte målinger (PROM) måler hvordan pasienter opplever forhold knyttet til helse, sykdom og effekter av behandling (13). PROM kan besvares elektronisk eller på papir. Når PROM brukes i klinisk praksis, kan målingene bidra til å forbedre og individualisere pasientoppfølgingen (13).

Helsepersonell kan oppnå personsentrert oppfølging ved å identifisere pasientenes utfordringer og følge utviklingen over tid i tillegg til å forbedre kommunikasjonen og fremme egenbehandling og felles beslutningstaking.

\section{DiaPROM-prosjektet startet i 2017}

Tidligere forskning har vist at å bruke PROM for å kartlegge diabetesrelatert bekymring etterfulgt av gjennomgang og diskusjon med helsepersonell kan bidra til å redusere bekymringer, bedre det generelle velværet og $\varnothing \mathrm{ke}$ tilfredsheten med oppfølgingen $(14,15)$.

Vi startet DiaPROM-prosjektet, «The use of Patient-Reported Outcome Measures to promote quality of diabetes care», i 2017. Den overordnede målsettingen var å utvikle, teste og evaluere en empowerment-basert intervensjon hvor vi benyttet spørreskjemaet Problem Areas In Diabetes (PAID) som dialogverktøy i polikliniske konsultasjoner blant unge voksne med diabetes type 1 (16).

\section{«Den overordnede målsettingen var å utvikle, teste og evaluere en empowerment-basert intervensjon.»}

Vi samarbeidet tett med brukerrepresentanter, Norsk diabetesregister for voksne og DIPS i utviklingen av prosjektet. PAID består av 20 påstander om diabetesrelaterte problemområder $(15,17)$. Det er oversatt til norsk og tilgjengelig $\mathrm{i}$ Noklus diabetes, en journal som benyttes ved landets diabetespoliklinikker.

\section{Deltakerne besvarte spørsmålene elektronisk}

Deltakerne i DiaPROM-prosjektet besvarte PAID og noen andre spørreskjemaer elektronisk før de skulle til årskontroller for diabetes (16). Legene gikk igjennom PAID-skåren i konsultasjonen. De som rapporterte fra moderat til alvorlig forhøyet distress, fikk tilbud om tilleggsoppfølging hos en diabetessykepleier.

Vi utviklet en empowerment-basert kommunikasjonsguide som diabetessykepleierne benyttet i samtalen om deltakernes diabetesrelaterte problemområder. Kommunikasjonsprinsippene innebar at sykepleieren stilte oppmerksomme spørsmål, brukte aktiv lytting samt responderte for å utforske problemområdene ytterligere («ask - listen - respond - sum up»). 
Til slutt skulle sykepleieren oppsummere samtalen og oppmuntre deltakeren til å definere mål og tiltak som de skulle jobbe med frem mot neste konsultasjon. En viktig del av oppfølgingen var å tilby individualisert informasjon og opplæring ved behov.

\section{Fire delstudier i DiaPROM er gjennomført hittil}

Vi har hittil gjennomført fire delstudier i DiaPROM, alle ved Haukeland universitetssjukehus (18-21). Målet med disse studiene var å teste gjennomførbarheten av intervensjonen og derved undersøke usikkerhet knyttet til å gjennomføre en fullskala randomisert kontrollert effektstudie (RCT).

I den første delstudien fant vi at det var gjennomførbart å innhente elektroniske PROM på en PC med berøringsskjerm, som var plassert ved diabetespoliklinikkens venteareal (18).

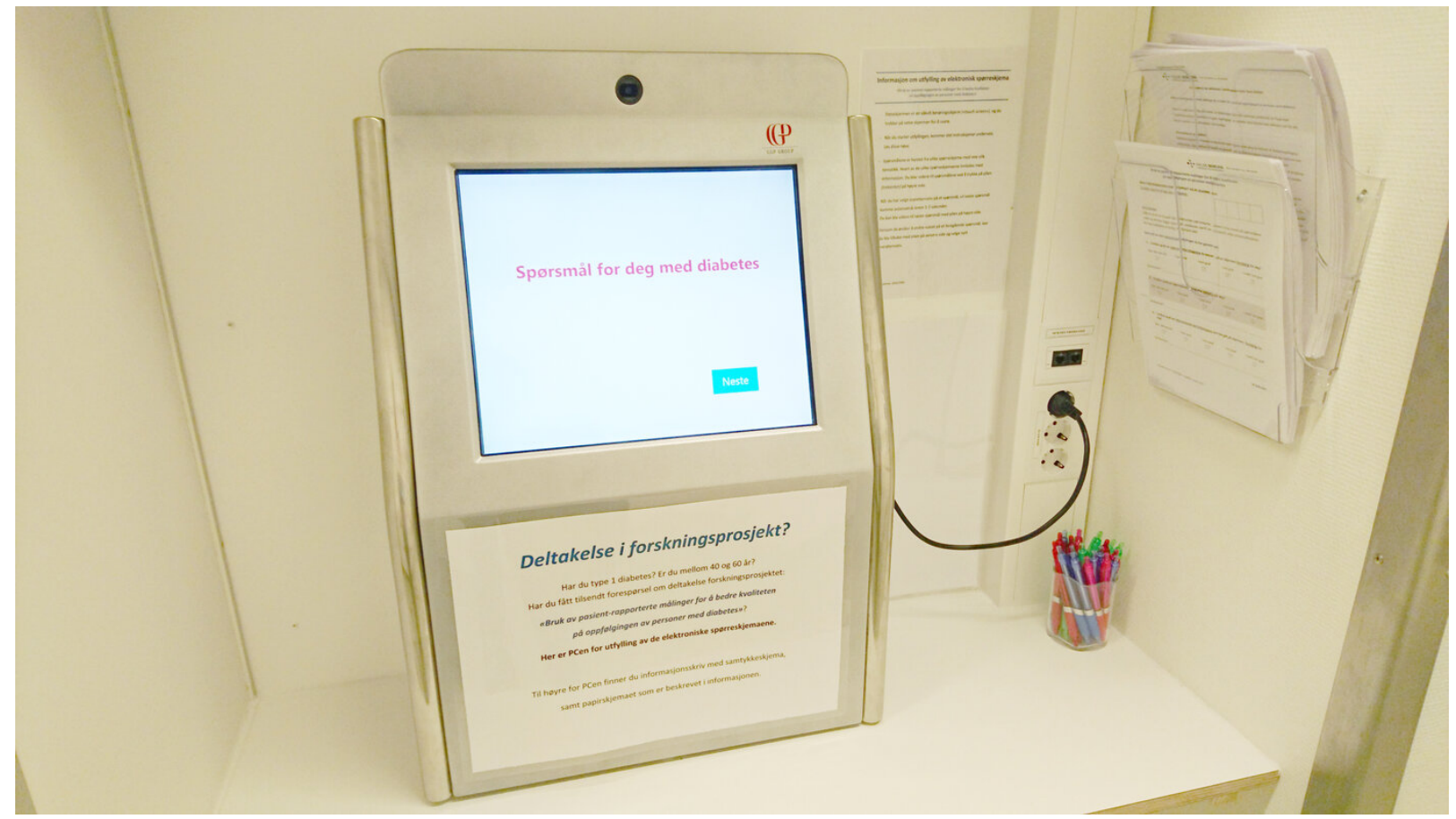

BERØRINGSSKJERM: Deltakerne besvarte spørreskjemaet elektronisk på sykehuset. Foto: Ingvild Hernar og Anne Haugstvedt

Deltakerne rapporterte at spørreskjemaene var forståelige og relevante med et akseptabelt antall spørsmål, samt at de var villig til å svare på PROM årlig. I tillegg fikk vi tilbakemelding om at de satte pris på at spørreskjemaene dekket psykososiale aspekter ved å leve med diabetes.

I den andre delstudien foretok vi en pilotstudie, en såkalt mini-RCT, blant 80 unge voksne (18-39 år) med diabetes type 1 (figur 1) (19). Blant de 40 deltakerne i intervensjonsarmen rapporterte totalt 24 (6o prosent) moderat til betydelig diabetesrelatert bekymring. 
Figur 1. DiaPROM-intervensjonen

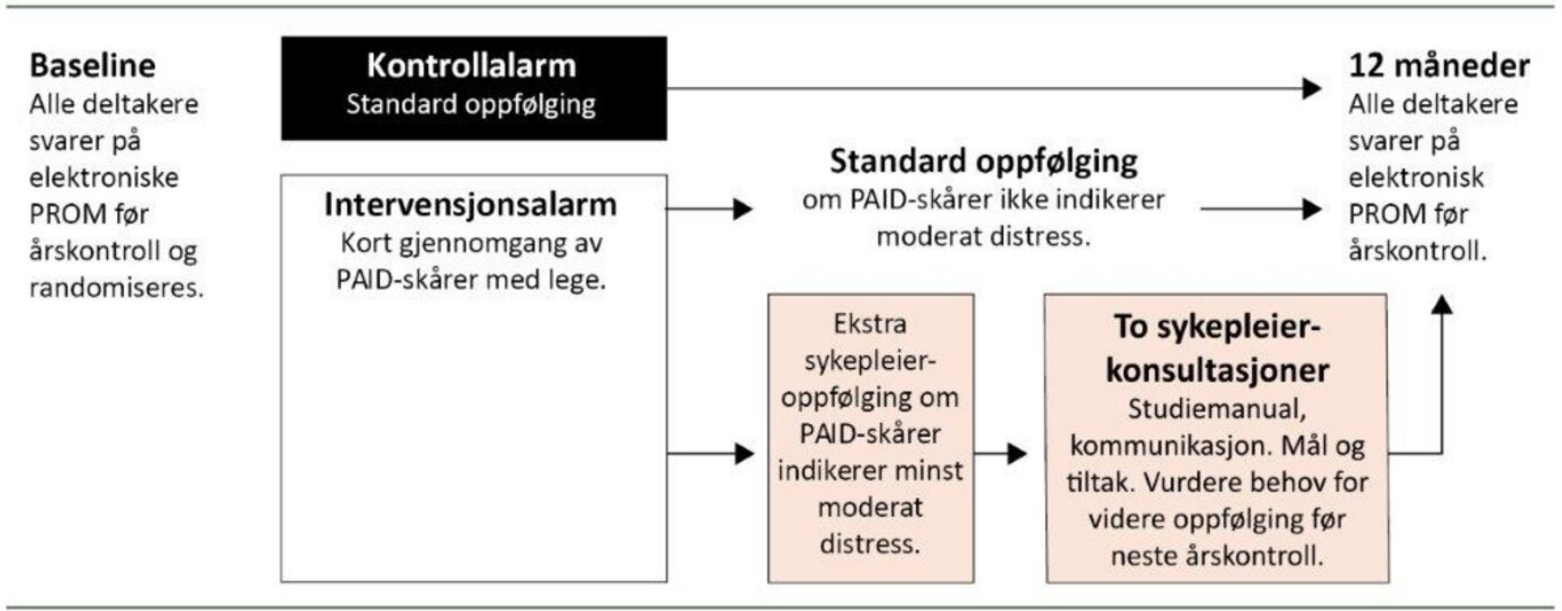

De kvalifiserte dermed for tilleggsoppfølging hos en diabetessykepleier, mens 18 $\varnothing$ nsket slik oppfølging. Igjen fikk vi positive tilbakemeldinger om spørreskjemaene og innsamlingsmetoden. Tre firedeler rapporterte at det hadde vært positivt å svare på PROM, og en tredel ga uttrykk for at det å svare på PAID førte til nye diskusjoner med leger og sykepleiere om diabetesrelaterte utfordringer.

Til tross for de positive tilbakemeldingene observerte vi at en del av deltakerne i intervensjonsgruppen falt fra underveis i studien, og at intervensjonen ikke ble gjennomført helt som planlagt.

Vi fikk erfare hvor krevende det er å utføre intervensjonsstudier i en travel poliklinikk, og konkluderte med at intervensjonen må modifiseres før man kan gå videre til en utprøving i stor skala. En modifisert utgave av intervensjonen prøves nå ut ved Haraldsplass Diakonale Sykehus i Bergen.

\section{Brukerne beskrev sine erfaringer}

I den tredje studien intervjuet vi 19 unge voksne med diabetes type 1 som deltok i pilotstudien (20). Vi spurte om deres erfaringer med poliklinisk oppfølging generelt samt det å besvare elektroniske PROM og bruke PAID som dialogverktøy i konsultasjoner. Dataene analyserte vi ved hjelp av tematisk analyse. Vi identifiserte tre temaer, hvert med to undertemaer (tabell 1). 
Tabell 1. Erfaringene til unge voksne med diabetes når det gjelder diabeteskonsultasjoner og DiaPROM $(n=19)$

\begin{tabular}{ll}
\hline Temaer & Undertemaer \\
\hline Oppfølging med begrensninger & Marginal dialog om hverdagens utfordringer \\
& Verdien av støttende relasjoner og kontinuitet \\
\hline Ny innsikt og $\varnothing$ kt bevissthet & Mer livsorientert innsikt \\
& Bevege seg ut av komfortsonen \\
\hline Adressere problemområder med et åpent sinn & Behov for utdyping \\
& Beredt for dialog \\
\hline
\end{tabular}

Deltakerne ga uttrykk for at diabetesoppfølgingen de var vant med, hadde begrensninger og inneholdt marginal dialog om hverdagslige diabetesutfordringer. De løftet frem et $\varnothing$ nske om $\varnothing \mathrm{kt}$ kontinuitet og mer støttende relasjoner med helsepersonell.

En av dem beskrev oppfølgingen slik: «Jeg føler at jeg kun er der for at [legene] liksom skal krysse ut noe på en sjekkliste og gjøre jobben deres, på en måte... Jeg føler at det ikke er noe poeng i å være der da. Fordi hva vinner jeg på at de veier meg og måler meg, liksom? Jeg føler ikke at vi snakker om noen ting som er viktige.»

\section{PROM ga deltakerne ny innsikt}

Gjennom å svare på PROM fikk deltakerne ny og økt innsikt som fremmet bevisstheten rundt å leve med og håndtere diabetes type 1. En av dem forklarte det slik:

«Jeg synes spørsmålene er veldig bra, og jeg tenker at man kanskje kommer på andre ting å ta opp med legen. Måten de spørsmålene blir satt opp på, og at man kanskje føler at man ikke er den eneste som kan sitte og tenke på forskjellige ting. At en ikke er alene med de tankene og det en føler rundt diabetesen sin.»

Deltakerne beskrev at enkelte PROM-spørsmål kunne medføre at de måtte gå ut av sin egen komfortsone. Til tross for at dette kunne oppleves ubehagelig, mente de likevel at det var verdt det: 
«Noen spørsmål kan være litt vanskelige og såre å svare på. Om man egentlig svarer helt det rette, det er vel egentlig bare det som kan være litt hemmende, hvor ærlig en er med seg selv. Som diabetiker så blir man litt sånn - du lyver litt for deg selv innimellom, du tror det er litt bedre enn det egentlig er. Altså det er litt vanskelig innimellom, men jeg tror det er bare bra at man får litt bevisstgjøring og litt tanker rundt hvordan det faktisk går.»

\section{«Deltakerne beskrev at enkelte PROM-spørsmål kunne medføre at de måtte gå ut av sin egen komfortsone.»}

Når det gjelder å bruke PAID-skjemaet i oppfølgingen, uttrykte deltakerne behov for å utdype eller nyansere besvarelsen sin overfor helsepersonellet. Dessuten påpekte de viktigheten av at helsepersonell adresserer de diabetesrelaterte problemområdene åpent og utforskende. Her bidro PAID til dialog, spesielt med legene, som mange ikke hadde vært vant til å diskutere slike utfordringer med tidligere.

En forklarte det slik: «Jeg synes det var helt greit at legen fikk se det jeg hadde svart. Da kunne legen ta tak i problemområdene eller det jeg var misforn øyd med eller bekymret meg over. Vi hadde noe konstruktivt å jobbe ut ifra, det ble ikke så svevende som [...] Ja, det kan være vanskelig for meg å sette ord på hva jeg egentlig vil ha ut av den timen. Det kom gjerne mer frem i spørreskjemaet.»

\section{Helsepersonell erfarte motstridende krav}

I den fjerde delstudien utførte vi individuelle intervjuer med ni leger og fem diabetessykepleiere som bidro i pilotstudien (21). Vi spurte om deres erfaringer med diabeteskonsultasjoner generelt og DiaPROM-intervensjonen spesielt. Også her benyttet vi tematisk analyse og identifiserte tre temaer, hvert med to undertemaer (tabell 2). 
Tabell 2. Helsepersonells erfaringer med diabeteskonsultasjoner og DiaPROM $(n=14)$

\begin{tabular}{|c|c|}
\hline Temaer & Undertemaer \\
\hline \multirow[t]{2}{*}{ Motstridende krav og prioriteringer } & $\begin{array}{l}\text { Balansere anbefalinger i retningslinjer med } \\
\text { pasientenes hovedanliggender }\end{array}$ \\
\hline & $\begin{array}{l}\text { Opplevelse av at pasienter trenger mer støtte for } \\
\text { å håndtere sine emosjonelle bekymringer }\end{array}$ \\
\hline \multirow[t]{2}{*}{ Innsikt i bruk av dialogverkt $\varnothing y$} & $\begin{array}{l}\text { Fordelene og utfordringene ved å bruke PAID som } \\
\text { dialogverkt } \varnothing y\end{array}$ \\
\hline & Kommunikasjonsteknikker er nyttige \\
\hline \multirow[t]{2}{*}{ Fasilitering av nye intervensjoner er utfordrende } & $\begin{array}{l}\text { Uklare roller og ansvarsfordeling i det tverrfaglige } \\
\text { teamarbeidet }\end{array}$ \\
\hline & Kapasiteten setter begrensninger, ikke villigheten \\
\hline
\end{tabular}

Studien viste at legene og diabetessykepleierne opplevde motstridende krav og betydelige tids- og ressursutfordringer både i sitt daglige arbeid og $\mathrm{i}$

gjennomføringen av DiaPROM-konsultasjonene. Spesielt legene erfarte et dilemma når det gjaldt om de skulle bruke tiden på biomedisinske aspekter og målinger eller på pasientenes emosjonelle utfordringer.

En av dem sa: «Det er jo en sånn balanse mellom på den ene siden at vi skal innhente en del informasjon som må til for at vi skal gjøre det vi, fra vår side, skal gjøre for å komme gjennom det som hører med, og på den andre siden slippe pasienten frem med det som er deres problemstillinger, da.»

\section{Pasientene kunne sette ord på problemene}

Diabetessykepleierne erfarte at dagens diabetesbehandling med utstrakt bruk av avansert teknologi (insulinpumper og kontinuerlige glukosemålere) som skal følges opp i konsultasjoner, stjal mye av deres tid. Den tiden burde de kanskje heller ha brukt på å diskutere de psykososiale aspektene ved det å leve med diabetes.

En beskrev det slik: «Konsultasjonene har virkelig endret seg de senere år når så mange bruker kontinuerlige glukosemålere. Så nå går mye av tiden med til å avlese utstyret. Og så er det problemer med det tekniske utstyret, så mye tid går med til det. Dette er tid som kunne vært brukt til å prate.»

Legene og sykepleierne erfarte at å bruke PAID i konsultasjoner så ut til å hjelpe pasientene til å sette ord på sine diabetesrelaterte problemer og utfordringer. En deltaker beskrev det slik: «Ja, å bruke PAID er en rask måte å komme til de sentrale aspekter, hva problemer faktisk er. Så jeg synes det er veldig bra.» 
Det kom også frem noe usikkerhet og ambivalens knyttet til nytten av å bruke PAID slik. Deltakerne beskrev imidlertid at det var svært utfordrende å iverksette og fremme nye intervensjoner i klinisk praksis nettopp på grunn av den opplevde tidsog ressursmangelen.

\section{Diskusjon og implikasjoner for praksis}

Både klinikere og personer med diabetes type 1 fremhever at en ensidig fokusering på biomedisinske helseparametere fremfor psykososial helse hindrer diabetesomsorg av høy kvalitet $(22,23)$. Likevel nevnes ikke diabetesrelatert bekymring spesifikt i Helsedirektoratets gjeldende retningslinje for diabetesbehandling og -oppfølging (10).

Hovedargumentet for å innlemme kartlegging av diabetesrelatert bekymring i ordinær diabetesoppfølging er at slike problemområder ofte er sammenvevd med personenes egenbehandling av diabetes, og god egenbehandling er igjen en forutsetning for å oppnå best mulig behandling og helse $(3,5-7)$.

Derfor bør kartlegging og vurdering av diabetesrelatert bekymring innlemmes når retningslinjen skal oppdateres. Samtidig må man også ta høyde for at helsepersonell får tildelt tilstrekkelig tid og ressurser til å yte slik personsentrert omsorg.

\section{«PAID bidro til at konsultasjonene ble mer tilpasset de unge voksnes ønsker og behov.»}

Tidligere forskning om helsepersonells evner og kapasitet til å oppdage diabetesrelatert bekymring har vært sprikende $(24,25)$. I våre studier fant vi at elektronisk innhenting av PROM-data var teknisk gjennomførbart og godt akseptert.

I tillegg var det å bruke PAID-skjemaet til å snakke om problemområdene sett på som svært relevant og viktig for nåværende og fremtidig diabetesoppfølging, selv om de unge voksne med diabetes ga uttrykk for at det kunne være utfordrende å dele sine egne diabetesrelaterte bekymringer med helsepersonell.

Videre fant vi at PAID bidro til at konsultasjonene ble mer tilpasset de unge voksnes $\varnothing$ nsker og behov, hovedsakelig fordi dialogen med legene ble mer fokusert og direkte. Det støttes av andre studier hvor forfatterne har pekt på behovet for at helsevesenet integrerer psykososial støtte i diabetesoppfølgingen $(5,8,22,23)$. 


\section{Konklusjon}

Det er fortsatt et presserende behov for forskning om hvordan vi i større grad kan prioritere oppfølging av emosjonelle aspekter ved å leve med diabetes type 1.

Vår erfaring er at å bruke PAID som dialogverktøy i diabetesoppfølgingen kan legge til rette for en mer helhetlig og personsentrert omsorg hvor også psykososiale aspekter og utfordringer knyttet til å håndtere og leve med diabetes type 1 blir tatt på alvor.

\section{Referanser}

1. Hamilton K, Stanton-Fay SH, Chadwick PM, Lorencatto F, de Zoysa N, Gianfrancesco C, et al. Sustained type 1 diabetes self-management: specifying the behaviours involved and their influences. Diabet Med. 2020;38(5):e14430.

2. Cooper JG, Bakke A, Dalen I, Carlsen S, Skeie S, Løvaas KF, et al. Factors associated with glycaemic control in adults with Type 1 diabetes: a registry-based analysis including 7601 individuals from 34 centres in Norway. Diabet Med. 2020;37(5):828-37.

3. Strandberg RB, Graue M, Wentzel-Larsen T, Peyrot M, Thordarson HB, Rokne B. Longitudinal relationship between diabetes-specific emotional distress and follow-up HbA1c in adults with Type 1 diabetes mellitus. Diabet Med. 2015;32(10):1304-10.

4. Nano J, Carinci F, Okunade O, Whittaker S, Walbaum M, Barnard-Kelly K, et al. A standard set of person-centred outcomes for diabetes mellitus: results of an international and unified approach. Diabet Med. 2020;37(12):2009-18.

5. Fisher L, Polonsky WH, Hessler D. Addressing diabetes distress in clinical care: a practical guide. Diabet Med. 2019;36(7):803-12.

6. Sturt J, Dennick K, Due-Christensen M, McCarthy K. The detection and management of diabetes distress in people with type 1 diabetes. Curr Diab Rep. 2015;15(11):101.

7. Wentzell K, Vessey JA, Laffel LMB. How do the challenges of emerging adulthood inform our understanding of diabetes distress? An integrative review. Curr Diab Rep. 2020;20(6):21.

8. Snoek FJ, Bremmer MA, Hermanns N. Constructs of depression and distress in diabetes: time for an appraisal. Lancet Diabetes Endocrinol. 2015;3(6):450-60. 
9. Ehrmann D, Kulzer B, Haak T, Hermanns N. Longitudinal relationship of diabetes-related distress and depressive symptoms: analysing incidence and persistence. Diabet Med. 2015;32(10):1264-71.

10. Helsedirektoratet. Nasjonal faglig retningslinje for diabetes. Oslo: Helsedirektoratet; 2016 [oppdatert 16. mars 2021]. Tilgjengelig fra: https://helsedirektoratet.no/retningslinjer/diabetes (nedlastet 01.12.2021).

11. Funnell MM, Anderson RM, Arnold MS, Barr PA, Donnelly M, Johnson PD, et al. Empowerment: an idea whose time has come in diabetes education. Diabetes Educ. 1991;17(1):37-41.

12. Kuo CC, Lin CC, Tsai FM. Effectiveness of empowerment-based selfmanagement interventions on patients with chronic metabolic diseases: a systematic review and meta-analysis. Worldviews Evid Based Nurs. 2014;11(5):30115 .

13. Greenhalgh J, Dalkin S, Gooding K, Gibbons E, Wright J, Meads D, et al. Functionality and feedback: a realist synthesis of the collation, interpretation and utilisation of patient-reported outcome measures data to improve patient care. Southampton: NIHR Journals Library (Health Services and Delivery Research, No. 5.2.); 2017.

14. Snoek FJ, Kersch NY, Eldrup E, Harman-Boehm I, Hermanns N, Kokoszka A, et al. Monitoring of Individual Needs in Diabetes (MIND)-2: follow-up data from the cross-national Diabetes Attitudes, Wishes, and Needs (DAWN) MIND study. Diabetes Care. 2012;35(11):2128-32.

15. Carlsen K, Haugstvedt A, Graue M. Bruk av kartleggings- og arbeidsverktøyet PAID i diabeteskonsultasjoner. Sykepleien Forskning. 2015;10(3):228-37.

16. Haugstvedt A, Hernar I, Strandberg RB, Richards DA, Nilsen RM, Tell GS, et al. Use of patient-reported outcome measures (PROMs) in clinical diabetes consultations: study protocol for the DiaPROM randomised controlled trial pilot study. BMJ Open. 2019;9(1):e024008.

17. Polonsky WH, Anderson BJ, Lohrer PA, Welch G, Jacobson AM, Aponte JE, et al. Assessment of diabetes-related distress. Diabetes Care. 1995;18(6):754-60.

18. Hernar I, Graue M, Richards D, Strandberg RB, Nilsen RM, Tell GS, et al. Electronic capturing of patient-reported outcome measures on a touchscreen computer in clinical diabetes practice (the DiaPROM trial): a feasibility study. Pilot and Feasibility Studies. 2019;5(1):29. 
19. Hernar I, Graue M, Richards DA, Strandberg RB, Nilsen RM, Rekdal M, et al. Use of patient-reported outcome measures (PROMs) in clinical diabetes consultations: the DiaPROM randomised controlled pilot trial. BMJ Open. 2021;11(4):eO42353.

20. Hernar I, Graue M, Strandberg RB, Lie SS, Sigurdardottir AK, Richards DA, et al. Young adults with type 1 diabetes and their experiences with diabetes follow-up and participation in the DiaPROM pilot trial: a qualitative study. Diabet Med. 2021;38(6):e14535.

21. Haugstvedt A, Hernar I, Graue M, Strandberg RB, Stangeland Lie S, Sigurdardottir AK, et al. Nurses' and physicians' experiences with diabetes consultations and the use of dialogue tools in the DiaPROM pilot trial: a qualitative study. Diabet Med. 2021;38(6).

22. Joensen L, Fisher L, Skinner T, Doherty Y, Willaing I. Integrating psychosocial support into routine diabetes care: perspectives from participants at the SelfManagement Alliance meeting 2016. Diabet Med. 2019;36(7):847-53.

23. Litterbach E, Holmes-Truscott E, Pouwer F, Speight J, Hendrieckx C. 'I wish my health professionals understood that it's not just all about your HbAic!'. Qualitative responses from the second Diabetes MILES - Australia (MILES-2) study. Diabet Med. 2020;37(6):971-81.

24. Pouwer F, Beekman AT, Lubach C, Snoek FJ. Nurses' recognition and registration of depression, anxiety and diabetes-specific emotional problems in outpatients with diabetes mellitus. Patient Educ Couns. 2006;60(2):235-40.

25. Sturt J, McCarthy K, Dennick K, Narasimha M, Sankar S, Kumar S. What characterises diabetes distress and its resolution? A documentary analysis. Int Diabetes Nurs. 2015;12(2):56-62. 